\title{
MODELOS E AVALIAÇÃO DO ENSINO SUPERIOR A DISTÁNCIA NO
} BRASIL

\author{
José Manuel Moran
}

CDD: 378

\begin{abstract}
RESUMO
O Brasil se encontra em uma fase de consolidação da educação a distância em todos os setores e níveis de ensino. Depois de uma fase de experimentação, onde houve uma aprendizagem intensa e busca de modelos mais adequados para cada instituição, nos encontramos em uma fase de amadurecimento, de maior regulação governamental, de maior cuidado com o crescimento, a infra-estrutura, a metodologia de ensino, a avaliação. Os modelos predominantes são os de teleaula, videoaula e WEB com maior ou menor apoio local. A legislação atual no Brasil privilegia o modelo semi-presencial, com acompanhamento dos alunos perto de onde moram (em pólos) e mostra desconfiança pelo modelo de acompanhamento online, principalmente em cursos de graduação. A educação a distância está se transformando, de uma modalidade complementar ou especial para situações específicas, em referência importante para uma mudança profunda do ensino superior como um todo. Este utilizará cada vez mais metodologias semi-presenciais, flexibilizando a necessidade de presença física, reorganizando os espaços e tempos de ensino e aprendizagem.
\end{abstract}

\section{PALAVRAS-CHAVE}

Educação a distância; Ensino superior; Teleaula; Educação online; Semi-presencial

\section{THE MODELS AND THE EVALUATION OF HIGHER DISTANCE EDUCATION IN BRAZIL}

\begin{abstract}
Brazil is in a consolidation phase of distance education in all sectors and levels of education. After a phase of experimentation, where there was an intense learning and searching for more appropriate models for each institution, we are in a phase of maturity, more government regulation, more concern about growth, infrastructure, methodology of teaching and learning. The main models are "teleclass" (class satellite), online, video-class with more or less local support. A current legislation in Brazil favors the bimodal model, with close monitoring of students and shows the pattern of mistrust the online monitoring, especially in undergraduate courses. Distance education is becoming an important reference for a change of higher education as a whole. It uses increasingly hybrid methodologies, making more flexible the need for physical presence, rearranging the spaces and times of teaching and learning.
\end{abstract}

\section{KEYWORDS}

Distance education; Higher education; Class satellite; Online education; Bimodal education 
Depois de uma década de experimentação, o ensino superior a distância encontrase numa fase de crescimento intenso, de consolidação pedagógica e de intensa regulação governamental, com diretrizes bem específicas.

A EAD é cada vez mais complexa, porque está crescendo em todos os campos, com modelos diferentes, rápida evolução das redes, mobilidade tecnológica, pela abrangência dos sistemas de comunicação digitais. EAD tem significados muito variados, que respondem a concepções e necessidades distintas. Denominamos EAD à educação continuada, ao treinamento em serviço, à formação supletiva, à formação profissional, à qualificação docente, à especialização acadêmica, à complementação dos cursos presenciais.

Além de ter significados, existem modelos bem diferentes que respondem a concepções pedagógicas e organizacionais distintas. Temos desde modelos auto-instrucionais a modelos colaborativos; modelos focados no professor (teleaula), no conteúdo, a outros centrados em atividades e projetos. Temos modelos para poucos alunos e modelos de massa para dezenas de milhares de alunos. Temos cursos com grande interação com o professor e outros com baixa interação. E não é fácil pensar em propostas que atendam a todas estas situações tão diferentes. Há um crescimento gigantesco dos cursos por satélite com teleaulas ao vivo e um tutor ou monitor presencial por sala, em pólos, mais apoio da Internet e de tutoria online. Essas instituições estão crescendo rapidamente chegando a dezenas de milhares de alunos rapidamente. É um modelo que mantém a figura do professor e a flexibilidade da auto-aprendizagem. Há cursos que combinam material impresso, CD/DVD e Internet. Há cursos para poucos e muitos alunos; cursos com menos ou mais encontros presenciais.

O importante é que EAD é educação e tem que ser de qualidade como a educação presencial. (NASCIMENTO; CARNIELLI, 2007). EaD de qualidade é aquela que ajuda o aluno a aprender igual ao presencial. Não se mede isso pelo número de alunos envolvidos, mas pela seriedade e coerência do projeto pedagógico, pela qualidade dos gestores e educadores e mediadores, sejam tutores ou qualquer palavra que se use. E também pelo envolvimento do aluno, se o aluno também está querendo aprender ou somente tirar o diploma. Envolve todo o processo, nisso não se diferencia do presencial. As instituições sérias no presencial costumam desenvolver também um trabalho a distância relativamente sério. $\mathrm{E}$ aquelas que são menos sérias, que focam mais os interesses econômicos no presencial, 
costumam ver a EaD como um caminho para poder ganhar mais e dinheiro ainda. Alguns autores servem da base para a avaliação do ensino superior a distância no Brasil, entre eles se destacam: Litto e Formiga (2009), Valente (2009), Almeida (2009), Gatti (2002), Silva (2003), e Oliveira e Oliveira (2009).

A EAD ainda é vista por muitos como uma solução pontual para situações específicas: pessoas mais adultas, que moram em cidades distantes ou que precisam de horários mais flexíveis do que nos cursos presenciais. Aos poucos se percebe que as atividades a distância são fundamentais para a aprendizagem atual, para atender a situações muito diferenciadas de uma sociedade cada vez mais complexa. A EAD, apesar do preconceito de muitos, é fundamental para modificar processos insuficientes e caros de ensinar para muitas pessoas ao longo da vida.

\section{MODELOS DE EAD NO BRASIL NO ENSINO SUPERIOR}

No Brasil, o ensino superior a distância só foi reconhecido com a Lei de Diretrizes e Bases de 1996. Só a partir de então avança. Nos primeiros anos as universidades atendem a demandas específicas, principalmente a capacitação de professores em serviço e os cursos de Pedagogia e Normal Superior. Foi uma etapa de aprendizagem das instituições públicas e privadas e também do Ministério de Educação. Surgiram situações novas como a possibilidade de atender por satélite a milhares de alunos ao mesmo tempo ou de dar um curso só pela Internet. (ALVES, 2009)

Agora nos encontramos numa fase de consolidação da EAD no Brasil, principalmente no ensino superior. A educação a distância é política pública, com forte apoio governamental, o que não acontecia no começo. Cria-se em 2005 a UAB ${ }^{1}$ - um órgão do MEC que gerencia as iniciativas da EAD nas universidades públicas. Consolida-se uma política mais reguladora no MEC, com decretos e portarias que definem claramente o que é válido ou não. Por exemplo, na graduação é fundamental ter pólos perto do aluno, com infra-instrutora bem definida e apoio de tutoria presencial.

\footnotetext{
${ }^{1}$ http://uab.capes.gov.br/index.php 
Fundamentalmente temos três modelos principais de EAD no ensino superior no Brasil, com algumas variáveis e combinações: o modelo teleaula, o modelo videoaula e o modelo WEB.

\section{O modelo teleaula}

Reúne os alunos em salas e um professor transmite uma ou duas aulas por semana, ao vivo. Os alunos enviam perguntas e o professor responde a algumas que considera mais importantes. Em geral, depois das teleaulas, os alunos se reúnem nas tele-salas, em pequenos grupos, para realizar algumas atividades de discussão e aprofundamento de questões relacionadas com a aula dada sob a supervisão de um mediador, chamado professor tutor local. Além das aulas, os alunos costumam receber material impresso e orientações de atividades para fazer durante a semana, individualmente, com o acompanhamento de um professor tutor online ou eletrônico.

Esse modelo começou focando mais a transmissão, a tecnologia de satélite, a multiplicação de pólos onde eram instaladas as tele-salas. As aulas são variações de professor falando, com ilustração de apresentações em PowerPoint, trechos de vídeo e alguma interação com a lousa digital. Os textos das aulas estão num livro impresso ou digital (CD, DVD ou Internet). Além das teleaulas e das atividades locais com o tutor de sala dos pólos, os alunos acessam (quando podem) o portal do curso na Internet, onde encontram alguns materiais complementares, e realizam alguma interação, em geral por fórum e enviam sua atividade para o tutor online. Houve um crescimento desordenado deste modelo, com a instalação de pólos em muitas cidades sem critérios definidos de parceria e sem padrões adequados de infra-estrutura exigidos. (MORAN, 2008)

Os tutores online são essenciais para acompanhamento das atividades dos alunos durante a semana. Eles assistem às aulas, acompanham os alunos nas atividades individuais e de grupo, tiram dúvidas dos alunos, devolvem com comentários as atividades realizadas que costumam ser disponibilizadas no portfólio eletrônico. Organizam os alunos em grupos para poder atendê-los melhor. Agendam chats com esses alunos.(CORTELAZZO, 2007) 
Os tutores de sala ficam nos pólos, perto dos alunos, para acompanhá-los nas atividades presenciais, durante as teleaulas e depois nas atividades de sala feitas em grupo. Durante a semana ajudam os alunos que vêm aos pólos, os ajudam na pesquisa nos laboratórios.

Uma figura que as instituições estão criando é a de Coordenador pedagógico do pólo para todos os cursos. Ele é o responsável institucional pelo bom andamento dos cursos no local, coordena as atividades dos tutores, supervisiona o funcionamento da infra-estrutura e a acadêmica.

Em relação à infra-estrutura, há uma exigência maior de bibliotecas no pólo, um livro para cada oito alunos, na bibliografia básica e uma proporção equivalente de computadores por número de alunos. Também as instituições estão mais atentas a criar laboratórios específicos para cada curso, virtuais e físicos.

Com a regulamentação mais detalhada elaborada pelo MEC para autorização de cursos a distância ${ }^{2}$ e a delimitação da infra-estrutura necessária para os pólos ${ }^{3}$, os cursos adquirem um caráter mais semipresencial, com maior apoio local e infra-estrutura mais adequada.

A partir de entrevistas com coordenadores pedagógicos de algumas instituições superiores que adotam o modelo teleaula, pude constatar avanços importantes que estão acontecendo na organização acadêmica e administrativa. Os principais são:

- Busca de aulas mais produzidas, com mais recursos de apoio (entrevistas, vídeos, animações, jogos). O modelo professor falando com apoio do PowerPoint está desgastado. Há uma valorização de maior participação dos alunos, de estabelecer vínculos com os pólos, de quebrar a aula com algumas atividades de discussão ou problematização intercaladas.

- Depois da tele aula, é colocado um link dela disponível no ambiente virtual, para que os alunos possam rever a aula quando o acharem conveniente (em algumas instituições o link fica disponível por poucos dias, pode ser acessado no pólo ou pode ser adquirido no formato DVD da aula na biblioteca do pólo.

\footnotetext{
${ }^{2}$ http://www.inep.gov.br/download/superior/ead/Instrumento_Autorizacao_curso_EAD.pdf

$3 \mathrm{http} / / / \mathrm{www}$.inep.gov.br/download/superior/ead/Instrumento_Cred Polo EAD atualizado agosto.pdf

(c) ETD - Educação Temática Digital, Campinas, v.10, n.2, p.54-70, jun. 2009 - ISSN: 1676-2592.
} 
Além das teleaulas há um avanço em algumas instituições no pós- aula, em que o professor retoma alguns tópicos da teleaula e os amplia num segundo momento através de uma webaula, de um podcast ou recurso semelhante. É uma forma de reforço, ampliação e personalização da teleaula, para focá-la melhor, tirar dúvidas. Esse material está disponível para o aluno no ambiente digital do curso. Há uma ligação maior entre teleaula, a web ou áudio-aula e os estudos independentes. Academicamente o projeto está mais integrado agora do que no começo. Começa-se pela teleaula, o professor retoma as questões de uma forma mais dialógica e faz a integração com as atividades individuais de estudo e pesquisa. As instituições começam a perceber a importância de divulgar e re-utilizar mais as próprias produções dos alunos, principalmente as feitas em vídeo. São utilizadas como subsídio das teleaulas e muitas ficam disponibilizadas na biblioteca digital.

- Há um melhor aproveitamento da cenografia. Alguns estúdios contam com equipamento de cenário virtual, que permite inserir o professor em ambientes relacionados com os temas da sua fala. Tem professores que representam personagens vinculados com o conteúdo, trazem profissionais para aproximar as idéias da experiência prática.

- Alguns professores desenvolvem formas de comunicação mais direta com os alunos: mobilizam os pólos com alusões diretas, com reorganização do espaço físico, com gincanas, concursos, sketches, representações, simulações.

Essa comunicação direta, ao vivo, é vista como grande diferencial neste modelo pelos coordenadores deste modelo de teleaula. Os alunos gostam de sentir o contato com o professor ao vivo, enviar-lhe perguntas, sentir-se incluído, mesmo que esporadicamente. Os alunos gostam desse contato com o professor, de saber-se citados, ver-se representados. Há uma certa mitificação do professor, os alunos os vêem como atores de TV. Tenho visto professores que eram contrários a esse modelo e que agora se sentem bem, porque reforça e amplia o seu papel de transmissor da informação e cria essa aura de visibilidade que a TV confere.

Os alunos manifestam o sentimento de participam de algo mais amplo que em uma aula presencial comum, porque compartilham questões com alunos de todo o país, podem confrontar visões com culturas diferentes. Esta interculturalidade poderia ser muito mais explorada, nas próprias teleaulas e no ambiente virtual. 
O recurso de webconferência ou de áudio conferência pode ser útil para orientação de grupos, para tirar algumas dúvidas, para orientação de estágio e TCC. Trabalhos de apresentação de alunos podem ser realizados também dessa forma. Algumas instituições já realizam a defesa da monografia em cursos de pós-graduação através de programas de webconferência, o que permite a conexão em tempo real e a possibilidade de cada um conectar-se onde o considerar mais conveniente.

Apesar dos avanços mostrados pelos coordenadores desses cursos por teleaula, observamos que privilegiam a transmissão da informação pelo professor numa época em que a informação está disponível por várias mídias e que o papel do professor pode ser muito mais importante se ele se transforma em orientador, em contextualizador das questões dos alunos.

Um enfoque diferente do modelo de teleaula poderia inverter o processo. Pode ser um ponto de chegada e não só um ponto de partida da informação. Os alunos tomam contato com um assunto a partir de alguns materiais prévios (impressos, em áudio e vídeo), realizam algumas atividades de compreensão e pesquisa individualmente e em grupo. Discutem essas questões com os tutores e encaminham os resultados da pesquisa e as questões principais para o professor que na teleaula avalia todo o processo e traz contribuições específicas para aqueles grupos naquele momento.

Quanto à organização curricular, predomina o modelo disciplinar, mas também se trabalha por módulos. Algumas trabalham uma disciplina por vez (em geral, uma por mês), enquanto outras alternam duas disciplinas, para dar mais variedade para o aluno (a avaliação parcial, costuma ser bimestral e ao fim do semestre é feita a avaliação de todas as disciplinas. As que organizam as disciplinas sequencialmente costumam fazer uma avaliação presencial ao termino de cada uma (em média, uma vez por mês) e evitam a avaliação geral semestral. Houve até agora predomínio na avaliação presencial da múltipla escolha. Atualmente predominam as questões dissertativas. Algumas instituições combinam questões objetivas com questões dissertativas. A avaliação presencial sempre tem um peso maior (exigência do MEC) e varia entre 60 e 80 por cento do valor da nota ou conceito final. Os alunos são avaliados nas atividades a distância e em sala. Existem atividades que são preparatórias para a avaliação online principal. Duas são mais freqüentes: a qualidade da contribuição aos fóruns e o portfólio eletrônico ou físico, que recolhe os principais trabalhos desenvolvidos. 
No sistema modular, Em geral, desenvolvem-se três módulos por semestre. Cada módulo com dois ou três professores. Um módulo, em média, trabalha quatro temas. São utilizados em algumas instituições que trabalham por módulos, de 6 a 8 professores por semestre.

\section{O modelo WEB}

Hoje quase todos os cursos superiores a distância utilizam a Internet em algum momento, mas há instituições que têm na Internet o principal suporte. Os cursos de curta duração podem ser realizados inteiramente online, já nos superiores, principalmente de graduação, há hoje uma forte pressão pelo modelo-semipresencial.

O modelo WEB foca o conteúdo disponibilização pela Internet e por CD ou DVD também. Além do material na WEB os alunos costumam ter material impresso por disciplina ou módulo. Os ambientes principais de aprendizagem são o Moodle, o Blackboard e o Teleduc. Algumas instituições têm o seu próprio ambiente digital de aprendizagem. Começase a utilizar a webconferência para alguns momentos de interação presencial com os alunos, para orientações, dúvidas e manutenção de vínculos afetivos.

Até agora temos basicamente dois modelos diferentes de ensino superior a distância via web: o modelo mais virtual e o modelo semi-presencial. No modelo virtual, a orientação dos alunos é feita à distância pela Internet ou telefone. Os alunos se reportam ao professor e ao tutor durante o semestre e geralmente se encontram presencialmente só para fazer as avaliações. É um modelo predominantemente onde tudo acontece na Internet e os encontros presenciais são mais espaçados, porque não existem os pólos para o apoio semanal.

No modelo semi-presencial, como os do Consórcio CEDERJ ${ }^{4}$ das universidades públicas do Estado do Rio de Janeiro, os alunos têm pólos perto de onde moram e, além do tutor online, têm o tutor presencial no pólo, com quem pode tirar dúvidas e participar das atividades solicitadas e dos laboratórios de informática e específicos do curso. Esse modelo é

\footnotetext{
${ }^{4}$ http://www.cederj.edu.br/fundacaocecierj/index.php
} 
replicado pelas universidades públicas, sob a gestão da UAB - Universidade Aberta do Brasil, que fazem parceria com as prefeituras para a instalação dos pólos de apoio presenciais.

Nesta fase de regulação maior da EAD, há uma pressão forte para que todas as instituições que atuam no ensino superior a distância, principalmente na graduação, revejam seus projetos pedagógicos e se adaptem ao modelo semi-presencial, com pólos presenciais mais estruturados e atuantes, de acordo com as normas legais atuais, que se expressam nos instrumentos de credenciamento, autorização de cursos a distância e de autorização de pólos. As instituições que atuam no modelo de atendimento online via WEB, utilizando os pólos para avaliação presencial, terão que adaptar-se a estas normas - enquanto não houver mudanças - para obter o recredenciamento ou o reconhecimento dos cursos.

\section{O modelo videoaula}

Há instituições no ensino superior cujo projeto pedagógico foca mais a produção audiovisual e impressa pronta, não ao vivo. Produzem as aulas em estúdio, com mais ou menos profissionalismo.

Também há dois modelos predominantes utilizando a videoaula, um semipresencial e outro online.

O modelo mais usual é o de tele-salas, onde o aluno vai presencialmente uma ou várias vezes por semana e um tutor supervisiona a exibição do vídeo e as atividades relacionadas ao conteúdo da disciplina. Tira dúvidas, sob a coordenação de um professor responsável por essa disciplina. Este modelo é muito útil principalmente para cidades pequenas, sem condições para a instalação de uma instituição de ensino superior presencial.

Outro modelo é com vídeoaulas que os alunos acessam via WEB ou recebem por cd ou DVD. Os alunos assistem as videoaulas em casa ou no trabalho, lêem o material impresso e fazem as atividades que são entregues a um tutor -on line, num ambiente de aprendizagem digital, em geral o Moodle. Os alunos só vão a um pólo para a avaliação online. Os modelos de videoaula que utilizam mais a WEB - em geral o Moodle - como ambiente de 
aprendizagem e de interação, precisam rever o seu projeto à luz das normas atuais legais, focando muito mais o apoio também local ao longo do curso e não só na avaliação.

As exigências atuais de infra-estrutura do MEC de pólos com muito mais recursos, dificultam o atendimento a essas pequenas populações. Os alunos terão que se deslocar muito mais do que antes.

O modelo semi-presencial é muito utilizado nos cursos de pedagogia e licenciaturas. Ele precisa adaptar-se também, como os anteriores, às normas vigentes. A infraestrutura de apoio administrativa, tecnológica e acadêmica, costuma ser precária, com poucos computadores, biblioteca diminuta, o tutor sozinho com os alunos.

\section{ALGUMAS QUESTÕES DO ENSINO SUPERIOR A DISTÂNCIA NO BRASIL}

\section{Só um modelo é válido?}

Se em outros países, com mais tradição em EAD, como a Inglaterra, a Espanha, a Austrália há diversos modelos, se cada universidade pode definir sua forma de atuar em EAD e os resultados, nas principais universidades, são satisfatórios, por que nós devemos centrarnos num modelo semi-presencial como condição indispensável para o reconhecimento legal?

O Prof. Vianney mostra que os alunos da Open University conseguem ser classificados entre os das cinco melhores instituições Inglaterra, e as diversas faculdades têm bastante flexibilidade para organizar os diversos cursos a distância. (VIANNEY, 2008). A Open University atua desde a década de setenta e escolhe bons professores para escrever e gerenciar os seus cursos. A diversidade metodológica não é obstáculo. O importante é ter um bom projeto pedagógico e bons professores, com boas condições de trabalho.

Num estudo feito pelo Prof. Dilvo Ristoff, quando diretor do INEP, comparou o desempenho dos alunos dos mesmos cursos nas modalidades a distância e presencial do ENADE (2005-2006). Em sete das 13 áreas onde essa comparação é possível, alunos da modalidade a distância se saíram melhor do que os demais. Quando a análise é feita apenas levando em conta os alunos que ainda estão na fase inicial do curso - o Enade permite separar o desempenho de ingressantes e concluintes-, o quadro é ainda mais favorável ao ensino a 
distância: em nove das 13 áreas o resultado foi melhor. Nesses casos, turismo e ciências sociais apresentaram a maior vantagem favorável aos cursos a distância. Geografia e história foram os cursos em que o ensino presencial apresentou melhor desempenho. ${ }^{5}$

Na Alemanha, o professor Wolfram Laaser da FernÜniversitat da Alemanha, em palestras na Universidade Federal de Santa Catarina, mostra que comparando as trajetórias profissionais dos alunos concluintes presenciais e a distância, após vinte anos, numa mesma organização, os que tinham feito seus cursos a distância ocupavam funções mais destacadas. Os fatores considerados para compreender este fenômeno eram os da autonomia e da determinação necessária aos alunos para poder acompanhar as exigências de estudos autônomos, característica dos cursos a distância daquela universidade. (VIANNEY, 2008).

O MEC, preocupado com a qualidade, propõe parâmetros para organizar um processo em expansão rápida e com algumas instituições com mais preocupação mercadológica do que pedagógica. Isso é fundamental, mas está insistindo no modelo semipresencial, apoiado por pólos locais, com freqüência semanal dos alunos, como o único válido atualmente. É preocupante.

É possível aprender a distância de várias formas. No Brasil, estamos ainda numa fase de mudanças profundas na educação a distância, pela evolução rápida das tecnologias em rede, das tecnologias móveis e pela necessidade de incluir o maior número de alunos possível no ensino técnico e no superior. Num país com tantas necessidades e diversidade, é importante poder ter projetos consistentes com propostas diferentes, que sejam bem acompanhados e avaliados.

\section{Tensões entre o econômico e o pedagógico}

Há muitas contradições e tensões na educação. As principais se devem a que em alguns momentos focamos a educação mais como direito - educação para todos - enquanto que, em outros, o foco é a educação como negócio - como bem econômico, serviço, que se

\footnotetext{
${ }^{5}$ Antônio GOIS. Aluno a distância vai melhor no Enade. Jornal Folha de S. Paulo, 10 de setembro de 2007. CC ETD - Educação Temática Digital, Campinas, v.10, n.2, p.54-70, jun. 2009 - ISSN: 1676-2592.
} 
compra e vende, se organiza como empresa e onde se busca a maior rentabilidade, lucro e retorno do investimento.

Há instituições que vêem a EAD mais como negócio, mercado e investimento e todos os esforços são direcionados para a ocupação rápida do mercado, para a rentabilidade máxima dos acionistas, para ter um baixo custo aluno. Há instituições que focam o curto prazo e outras, o longo prazo. Em educação o sucesso de curto prazo pode ser traiçoeiro, porque projetos que atraem muitos alunos, se mal avaliados, afastam novas inscrições.

Estamos numa fase de profundas transformações, que nos estão levando a reorganizar todos os processos de ensino e aprendizagem, incluindo atividades a distância, flexibilidade curricular, possibilidade de cursos online em qualquer lugar e a qualquer hora. Se predominar a concepção administrativa sobre a pedagógica, poderemos criar com tecnologias novas processos velhos ampliados. Há uma certa apropriação das tecnologias avançadas hoje para a multiplicação de processos conservadores, focados no conteúdo transmitido ou disponibilizado, pela substituição do professor pelo "tutor" (mais barato) e pelo enxugamento de custos e maximização de lucros.

É importante estarmos atentos como educadores e como sociedade a re-equilibrar a educação como direito e como negócio, a buscar inovações na gestão, mas com foco na aprendizagem significativa, humanística, afetiva e com valores sólidos. Temos que inovar, avançar, criar uma educação mais próxima do aluno de hoje e das possibilidades de uma sociedade conectada, mantendo os valores humanos, afetivos e éticos cada vez mais vivos e predominantes. Podem conviver a educação como direito e como negócio, de forma equilibrada. Mas é bom estarmos atentos como sociedade a que a racionalidade administrativa não se sobreponha à pedagógica.

\section{A exigência da avaliação presencial}

Uma questão que precisa ser melhor analisada é a exigência legal de que a avaliação principal de um curso a distância seja presencial e que tenha um peso maior do que as avaliações feitas durante o curso. Em primeiro lugar, focar o peso da avaliação num momento presencial contradiz os projetos pedagógicos de muitos cursos que se dizem construtivistas e interacionistas, e que afirmam que o importante é a avaliação em processo 
(formativa) e não a pontual (somativa). E, em segundo lugar, se evidencia uma contradição gritante e preconceito contra a educação a distância ao exigir que num curso a distância a avaliação seja presencial. Entendemos os motivos das possibilidades de fraude a distância, assim como os há também no presencial, mas não se pode impedir - legalmente - que um curso a distância possa ser totalmente online, como acontece em muitos países. Hoje há recursos confiáveis de verificação e de acompanhamento digital dos alunos. (SILVA; SILVA, 2008)

O curioso é que muitas instituições não estão de acordo com a necessidade das avaliações serem presenciais, mas as reduzem a provas de múltipla escolha. O MEC fala em avaliações presenciais, não em provas necessariamente. Poderiam ser realizadas, nesses momentos presenciais, diferentes atividades como seminários, apresentação de resultados de projetos, discussões orais e muitas outras, além de provas.

\section{Para onde caminhamos no ensino superior}

Estamos diante de muitas mudanças, em uma fase em que temos que repensar a educação como um todo, em todos os níveis e a legislação da educação a distância é bastante detalhista e restritiva. Precisamos ter sensibilidade legal para evitar uma asfixia burocrática numa fase de grandes mudanças, e ao mesmo tempo sinalizar alguns limites para cada momento histórico. Estamos numa área onde conceitos como o de espaço, tempo, presença (física/virtual) são muito mais complexos e que exigem uma atenção redobrada para superar modelos convencionais, que costumam servir como parâmetro para avaliar situações novas.

Estamos caminhando para uma etapa de uma integração muito maior entre o presencial e o virtual. Algumas instituições já perceberam que a flexibilidade é inevitável. Propõem cursos que podem ser feitos presencialmente ou a distância, com maior integração e, às vezes, sem que o aluno perceba que é um curso a distância. Os cursos presenciais terão cada vez mais atividades a distância em proporção superior à atual, de forma que perderá sentido a separação entre o presencial e o a distância, como acontece até agora.

O semi-presencial é o modelo mais viável para a maioria das escolas nos próximos anos para alunos que moram perto do campus. Em todos os níveis de ensino (C) ETD - Educação Temática Digital, Campinas, v.10, n.2, p.54-70, jun. 2009 - ISSN: 1676-2592. 
teremos momentos juntos e atividades personalizadas de inserção em projetos, práticas, pesquisa combinadas com atividades de interação, de colaboração. Todas as universidades e organizações educacionais, em todos os níveis, precisam experimentar novas soluções para cada situação, curso, grupo e os legisladores serem cautelosos na normatização para não inviabilizar os avanços necessários na EAD.

Dependendo do projeto pedagógico do curso, da instituição, da idade do aluno haverá diferentes formatos de curso, níveis de flexibilidade, de orientação. Mas todos terão muitos menos presença física do que há hoje, menos horários rígidos como acontece atualmente.

O semi-presencial avançará, porque se adapta muito mais à nova sociedade aprendente, conectada; porque as crianças e jovens já têm uma relação com a Internet, as redes, o celular e a multimídia muito mais familiar do que os adultos. O semi-presencial já é uma experiência vivida em muitas outras situações por eles. A escola é que não os está acompanhando. O semi-presencial avançará também porque para os mantenedores das escolas reduzirá custos de utilização de infra-estrutura, de ocupação de espaço, de horas aula de professores. E a legislação precisa possibilitar esta flexibilidade das formas de ensino e aprendizagem que mais se adaptem às necessidades de cada pessoa e grupo em todos os níveis de ensino.

A legislação não consegue prever essas mudanças. Por isso é importante permitir propostas inovadoras, acompanhá-las, avaliá-las para poder avançarmos mais rapidamente. A legislação pode trabalhar com parâmetros, princípios - em decretos - sem chegar a minúcias que podem trazer problemas de interpretação e impedir avanços significativos e que podem ser normatizados em portarias.. Precisamos regular com mais abertura para o novo e supervisionar o que acontece mais de perto para avançar de verdade e separar o joio do trigo, os que querem contribuir para um ensino e aprendizagem de qualidade dos que só querem lucrar com qualquer tipo de ensino, seja presencial ou a distância.

A educação a distância está se transformando, de uma modalidade complementar ou especial para situações específicas, em referência para uma mudança profunda do ensino superior como um todo. Este utilizará cada vez mais metodologias semi-presenciais, flexibilizando a necessidade de presença física, reorganizando os espaços e tempos de ensino 
e aprendizagem. A educação a distância está se expandindo, sem dúvida, mas também afetando profundamente à educação como um todo. Num mundo conectado em redes, onde aumenta a mobilidade, a educação a distância hoje passou de uma modalidade complementar a ser eixo norteador das mudanças profundas da educação como um todo, principalmente no ensino superior.

\section{REFERÊNCIAS}

ALMEIDA, M. E. As teorias principais de andragogia e heutagogia. In: LITTO, F.; FORMIGA, M. (Org.). Educação a distância: o estado da arte. São Paulo, SP: Pearson Education do Brasil, 2009. p. 105-111.

ALVES, J. R. A história da EAD no Brasil. In: LITTO, F.; FORMIGA, M. (Org.). Educação a distância: o estado da arte. São Paulo, SP: Pearson Education do Brasil, 2009.p.9-13.

CORTELAZZO, I. et al. Cursos de Graduação a distância: inclusão e qualidade. In: CONGRESSO INTERNACIONAL DA ABED, 2007, Rio de Janeiro. Congresso Internacional de Educação a Distância. Rio de Janeiro, RJ: ABED, 2007. Disponível em: <http://www.abed.org.br/congresso2007/tc/82200724656PM.pdf>. Acesso em: 10 out.2008.

GATTI, B. A Formação de professores a distância: critérios de qualidade. Disponível em: < http://www.tvebrasil.com.br/salto/boletins2002/ead/eadtxt1b.htm >. Acesso em: 3 ago.2008.

LITTO, F.; FORMIGA, M. (Org.). Educação a distância: o estado da arte. São Paulo, SP: Pearson Education do Brasil, 2009.

MORAN, J. M. A educação a distância e os modelos educacionais na formação dos professores. In: BONIN, I. et al. Trajetórias e processos de ensinar e aprender: políticas e tecnologias. Porto Alegre: Edipucrs, 2008. p. 245-259. (XIV Endipe).

NASCIMENTO, F.; CARNIELLI, B. L. Educação a distância no ensino superior: expansão com qualidade? ETD - Educação Temática Digital, Campinas, v. 9, n. 1, p.84-98, nov. 2007. Disponível em: 〈http://www.fae.unicamp.br/etd>. Acesso em: 20 jul.2008.

OLIVEIRA, T. Z.; OLIVEIRA, P. C. Perspectivas sociais e políticas da ead no Brasil: uma visão panorâmica com foco na produção científica para o setor. Disponível em: <http://twiki.im.ufba.br/pub/Main/PauloCezarOliveira/artigo_ead_pctz.doc >. Acesso em 3 fev. 2009.

SILVA, A.; SILVA, C. Avaliação da aprendizagem em ambientes virtuais: rompendo as barreiras da legislação. In: CONGRESSO DA ABED, 2008, Santos. Congresso 
Internacional de Educação a Distância. Santos: ABED, 2008. Disponível em: <www.abed.org.br/congresso2008/tc/510200863228PM.pdf >. Acesso em 20 jan.2009.

SILVA, M (Org.). Educação online: teorias, práticas, legislação, formação corporativa. São Paulo, SP: Loyola, 2003.

VALENTE, J. A. Aprendizagem por computador sem ligação à rede. In: LITTO, P.; FORMIGA, M. (Org.). Educação a distância: o estado da arte. São Paulo, SP: Pearson Education do Brasil, 2009. p.65-71.

VIANNEY, J. A ameaça de um modelo único para a EaD no Brasil a ameaça de um modelo único para a EaD no Brasil. Colabor@ - Revista Digital da CVA-RICE U, v. 5, n.17, jul.2008. Disponível em: <http://www.ricesu.com.br/colabora/n17/index1.htm> Acesso em: 16 fev.2009. 
